\title{
Dante Bini’s Form-Resistant Binishells
}

\author{
Alberto Pugnale $^{1}$ (D) Alberto Bologna ${ }^{2}$
}

\begin{abstract}
This paper aims to review Dante Bini's career, as well as his formresistant Binishell and other pneumatic construction systems. The role of Mario Salvadori in Bini's international success works as the introduction to a broader discussion about the relationship between innovation in design and innovation in construction for shell and gridshell designers. The second part of the paper focuses, instead, on Bini's double profile — architect and builder-which led him to develop his inventions both architecturally and as commercial products.
\end{abstract}

Keywords Dante Bini · Binishells · Form-resistant structures · Form-finding · Pneumatic structures · Mario Salvadori · RC Shells · Innovation in construction

\section{Why Binishells Stand Up: Mario Salvadori's Passion for Form-Resistant Structures}

Mario Salvadori's Why Buildings Stand Up: The Strength of Architecture (1980) has become a paradigm, at least within the United States, of how to explain even the most complex notions of structures in simple terms for non-specialists. Such highlevel popular science is also useful for students and professionals of architecture, and these are also among its many readers. The book, which does not include formulae, illustrates mechanical behavior and properties of materials as well as

Alberto Pugnale

alberto.pugnale@unimelb.edu.au

Alberto Bologna

alberto.bologna@polito.it

1 University of Melbourne, Melbourne, Australia

2 Politecnico di Torino, Corso Duca degli Abruzzi, 24, 10129 Torino, Italy 
construction typologies and buildings that symbolise structural innovation by means of drawings and diagrams, the work of Saralinda Hooker and Christopher Ragus. As Salvadori says, he narrates his personal history of architecture, which he views through the evolution of structural systems or configurations, and the works of designers of greater and lesser renown.

Earlier, in 1963, Salvadori had tried to carry out this scientific and cultural work with co-author Robert Heller, in Structure in Architecture. This was destined for those "who love beautiful buildings and would like to know why they stand up", but also for those "who dream of designing beautiful buildings and would like them to stand up", and finally for those "who have designed beautiful buildings and would like to know why they stood up" (Salvadori 1963: Preface). Here too there are no mathematical formulae, and although the explanation of structural types does not yet succeed in distancing itself from a narration and graphic language that is characteristic of engineering, it manages to outline a historiographical trajectory that juxtaposes similar structural types of structures and traces an evolution in terms of statics and construction.

Instead, in Why Buildings Stand Up, from the very first pages we find that the focus of the narrative is architecture, immediately described as "a young art that had its beginnings only 10,000 years ago when men and women, having discovered agriculture and husbandry, were able to give up roaming the surface of the earth in search of food" (Salvadori 1980: 17). From this premise, Salvadori concentrates his text on the physical, mechanical and structural principles that came to be used in ensuing centuries to build shelters (roofs) and crossings (bridges), with a narrative that, although not always chronological, serves as a step-by-step guide to constructive typologies, physical principles, entities such as "loads" and concepts such as "resistance by form". "Form-resistant structures" are thus the subject of one of the most important chapters in the book, and this concept fascinated Salvadori literally until his death. In the chapter dedicated to houses, he reveals his passion for buildings with circular plans topped by domes: from Sardinian nuraghe, surmounted by corbelled domes, to the stone trulli of Apulia (Todisco et al. 2017), to the wooden roofs that characterise the constructive traditions in the Amazonian jungles of South America, to Eskimo igloos built of blocks of ice and finally, taking a great leap forward in time, to the prefabricated systems in reinforced concrete used by Pier Luigi Nervi in the early 1940s to build his famous hangars for the military. By developing a reasoning based on structural type, Salvadori is able to juxtapose, for instance, the thin shells in reinforced concrete of Félix Candela with the structural systems of the Gothic cathedrals, or the physical nature of the dome of the Pantheon to that of Santa Maria del Fiore and the Hagia Sophia.

In the chapter dedicated to form-resistant structures, Salvadori concentrates on vaulted structures and shells. The exposition begins with the description of flat slabs, whose structural performance can be increased by the addition of either reinforcing bars (as in the case of slabs in reinforced concrete) or structural elements (beams or ribs capable of generating characteristic geometries at the intrados). When suitably curved, in keeping with one of the three categories defined at the beginning of the nineteenth century by secondo Karl Friedrich Gauss, that is, "domelike", "cylinderlike" and "saddlelike", a flat slab can assume the property of 
strength through shape. From this assumption, Salvadori interprets the structural functioning of famous shell structures, such as that of Candela's Cosmic Rays Laboratory in Mexico City. He then introduces an intuitive method for understanding the concept of resistance by form and form-resistant structures by using folded sheets of paper to illustrate the geometric principles of barrel roofs and folded plates (Figs. 1, 2). This is a system that he would continue to develop in the years that followed, in preparing his lessons for the Salvadori Center di New York, which he founded in 1987 with the aim of showing middle-school students, particularly those in under-privileged areas, how math and science are part of buildings, bridges, and communities (Salvadori 1997).

In the chapter's non-chronological narrative, ample space is given to hyperbolic paraboloid roof structures in reinforced concrete, including that used for the Cathedral of St. Mary in San Francisco and the umbrella-like structural elements in Newark International Airport. There is also a lengthy discussion of vaults and thin shells in masonry, characteristic of the constructive tradition in Catalonia (used, for example, by Antoni Gaudí in 1909 for the roof of the school at the Sagrada Familia in Barcelona). These are illustrated according to the procedure patented in the United States in 1885 by Rafael Gustavino.

In the sections about acclaimed designers such as come Candela and Nervi, Salvadori, curiously enough, takes a few lines to introduce a method for building shells in reinforced concrete by means of a pneumatic formwork. This system was invented by an Italian architect whose fame, in 1980, had not yet reached the level of the other designers just mentioned. This is Dante Bini, who began working in Italy in the 1960s, and later continued his activities in Australia, from 1974 to 1980. Years earlier he had impressed Salvadori with his constructive inventiveness. Bini's creation was born in 1964, in Emilia Romagna, with a typically Italian empirical approach based on experience on the construction site, whose roots lie in a constructive and experimental tradition that developed in Bologna thanks to the work Attilio Muggia, one of the pioneers of the use of reinforced concrete of the 1900s (Bettazzi and Lipparini 2010). It was precisely this approach, so far from the scientific orientation that typified engineering throughout the world at that time (see,
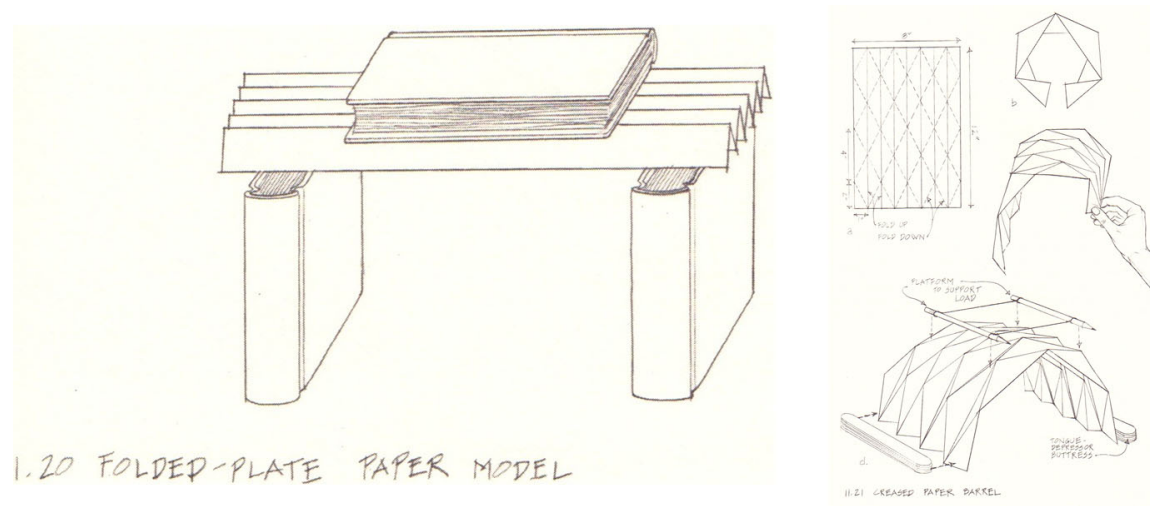

Fig. 1-2 Folded-plate paper models by Salvadori (Salvadori 1980: 193-194) 
for instance, Medwadowski 1964), that generated the creative impulses that led to the construction of Bini's domes, and consequently to new architectural paradigms that were the fruit of this new technique. In fact, Salvadori's first comment upon seeing the finished construction of a so-called "Binishell" seems to have been "If you were an engineer you would never have conceived such a nonsense" (Salvadori 1980: 203).

To place Bini's invention in perspective, it is useful to review its precedents. The first, visionary hypothesis regarding the use of pneumatic formwork was tested and proven as early as 1927 (Mohr 1927). The American architect Normand W. Mohr was the first to link "inflatables' to architecture. His experiments on aerostatic balloons, with technology patented under the title "Combined aeroplane and dirigible balloon" led him to conceive an alternative to the Golden Gate Bridge, that is, a subway to be built using pneumatic formwork. Starting in 1934, it was the turn of Wallace Neff, who created buildings well-known to the American public characterised by thin shells constructed with the use of pneumatic formwork. Regarding the procedure used by Neff, Salvadori writes that he "sets the reinforcements and pours the concrete on uninflated plastic balloons, and then lifts them by air pressure", highlighting from the very beginning the principle characteristic of Bini's method, first patented in Italy and then exported throughout the world. Neff filed patents, especially in the years 1941-1952 (see below), for the construction of spherical shapes in reinforced concrete by means of reusable pneumatic formwork. In 1954 Salvadori himself collaborated with Neff and Eliot Noyes to perfect the casting of concrete on this kind of formwork through the use of gunite (also known as dry-gun concrete) (Scipio 1967: 60). The idea of erecting the metal framework for a shell of double curvature beginning with a flat grid which is then folded in place by a crane is instead the result of research by the American architect and professor James H. Marsh. His work (Marsh 1964) was published in 1964, 2 years after its presentation at a conference in Washington.

The procedure that Bini patented is none other than a refined, effective synthesis of a series of inventions already tested and proven in the field of construction. However, Bini's insight went much further: he did not exploit the inflatable formwork to cast a shell in place. Instead his method consisted in executing the casting on the ground, flat, on an uninflated membrane that is reinforced by means of a metal "extendable framework" (Bini 1968), also placed on the ground, whose shape can be gradually adapting to that of the "inflatable" shell.

Salvadori continues, writing, "the Bini procedure ... has met with success almost all over the world in the erection of round domes of large diameter (up to 300 feet) for schools, gymnasiums, and halls"; but given that “... balloons are naturally efficient when round" he underlines one of the obvious limits, concluding that "these procedures cannot be adapted to other thin-shell shapes" (Salvadori 1980: 203).

Salvadori describes and considers thin shells, very reductively, as a technical expedient for roofing determined spaces and his assessment does not include any discussion of the aesthetics that might have led certain designers to prefer one solution over another, or in the spatial effects that such structures can generate. 


\section{The Compromise Between Innovation in Design and Innovation in Construction}

Situating Bini's work within the broader context of the conception and construction of shells and vaults allows us to see that his contribution is fascinating not only because of the degree of empirical inventiveness that Salvadori underlined, but also because it represents a synthesis of a themes that designers of form-resistant structures had to address from the very earliest vaulted structures. This is a compromise between the search for form and the implementation of structural techniques that are efficient and as capable of being industrialised as possible, to permit the rapid erection of arches, vaults and even double-curvature thin shells.

The astonishment felt when watching a Binishell inflate, that is, in witnessing the taking form of a lightweight shell in reinforced concrete starting from a flat casting, is comparable to that when watching skilled masons construct, stone by stone, Nubian vaults, the ancient ideal of perfect structural forms, though designed by sight on the basis of experience, skilfully realised without the use of formwork with the sole aid of inclined stable sections. One can experience the same kind of astonishment on the building site of a Guastavino dome (Ochsendorf 2010), that rare example of science and construction technique that come together in their path towards progress.

More common is the case in which architectural-structural design and practical realisation of the shell force the designer to reach a compromise between two alternatives: a perfect, double-curvature funicular form, which requires formwork that is expensive and difficult to build, and a geometric shape that is clean and analytically described but more of more immediate construction.

Candela's entire career shows that the Spanish designer always preferred the second of these two choices, that is, that of rationality on the construction site. Candela intentionally forced himself to be guided by geometry, particularly the use of the hyperbolic paraboloid-more commonly referred to as a "hypar", or doublecurvature saddle-which is easily discretised as straight lines, in that it is a ruled surface. However, this did not prevent him from generating spaces that are very articulated and diversified, such as those of the Church of la Medalla de la Virgen Milagrosa (Thrall and Moreyra Garlock 2010) and the Los Manantiales Restaurant. The compositive rules used by Candela are simple, analytical and rigorous; they have been defined as "disciplined" (Moreyra Garlock and Billington 2008: 76). The first step is that of sectioning a hypar of reference, deciding whether to obtain a geometry of curved or straight edges. The resulting structure is then repeated in the space following three procedures that we today recognised as basic CAD commands: copy, mirror and polar series. Control over the construction is guaranteed by the process, which intrinsically incorporates a structural response and materiality in the element of the hypar itself.

For many other designers, the geometry was never the primary source of inspiration, but in any case turned out to be a constructive solution that was as essential as it was ingenious. We need only mention the sails of the Sydney Opera 
House, at first sculpted freely, without rules, and then, after four years of work, cut out from the more manageable surface of a sphere.

For those who choose the first alternative, that of optimal structural form, there is no possibility of post-rationalisation on site, not with conventional constructive techniques. Further, the need to build complicated formwork results in a divergence between the ideal, pure shape modelled in the design studio, and the built structure, which is inevitably marked by the more regular outlines of wooden boards or panels. Among the most glaring examples of this problem is the bridge over the Basento River by Sergio Musmeci: initially designed on the principle of minimal surfaces, it immediately loses elegance and lightness when seen up close. ${ }^{1}$ However, there are cases in which the advantages of form-finding are more evident. In the funicular shapes derived from the "reverse hanging method", the best structural response, and thus the greatest possible thinness for the shell, provide a significant justification for the complexity of its construction. The works of Heinz Isler are good representatives of this advantage (Ramm 2011), especially when compared to the more geometric work of Saarinen.

It was in this context at the beginning of the 1960s that Dante Bini dreamt of building domes following the same procedure that would be used to conceive the form on paper, that is, by means of a method of form-finding, in this case, pneumatic (Figs. 3, 4). Heinz Isler and Frei Otto had experimented with all types, and had several times published examples of forms that resulted from inflating membranes (Isler 1994). However, they never thought of replicating the system at a scale of 1:1, as Bini instead did, thus synthesising form-finding and construction in what we might call "form-building". 2

From the first "inflations", the Binishell system was gradually perfected. For example, the technique for the reinforcing bars was optimised by the addition of metal springs, permitting better control over the folding and position of bars during erection. The inflatable structure went from a single layer, placed beneath the cast concrete, to two layers, enveloping the shell both above and below during the phase of forming. Further, for the first commissions outside Italy, Bini prepared the membrane in Italy so that it was brought to the site ready for use; he sometimes brought it with him on the airplane. This was the case of the Binishell demonstration in America, performed for Salvadori at Columbia University. That experience taught him that jumps in temperature due to flights neutralised the effects of the glue, causing the PVC strips of the membrane to come apart (Fig. 5). With the growing number of commissions from abroad, the preparation of the pneumatic formwork had to be radically reconsidered; this began with understanding what PVC sheets were easily available near the various work sites. Thus all of the pneumoforms in Australia were assembled with square PVC sheets 3 m wide (Bini 1995: 10).

\footnotetext{
${ }^{1}$ The main sources for Musmeci's work are published in Italian only. See (Manfredi 1999; Guccione 2003; Jones 2015).

${ }^{2}$ A good visual guide to the earliest Italian experiments is found in (McLean 2016). More recent professional photographs taken by Max Dupain, appear in (McLean 2013).
} 


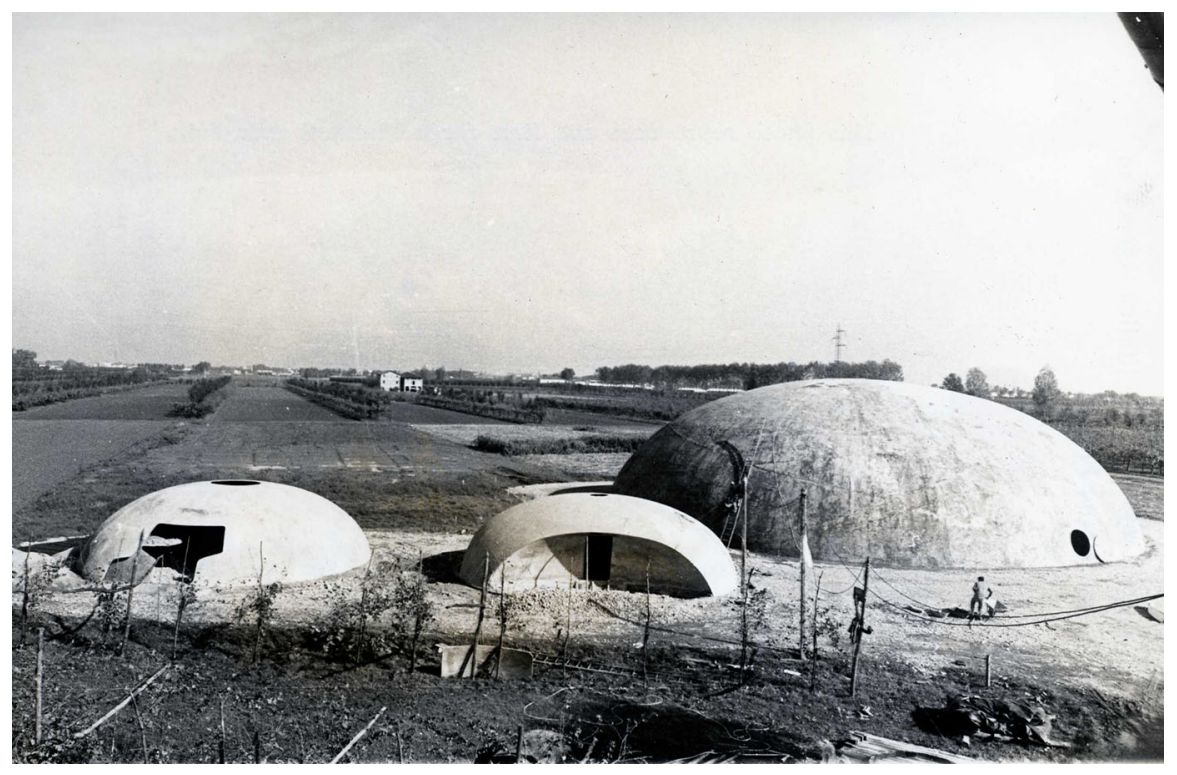

Fig. 3 First Binishell prototypes in Crespellano (Photo courtesy of Dante Bini)

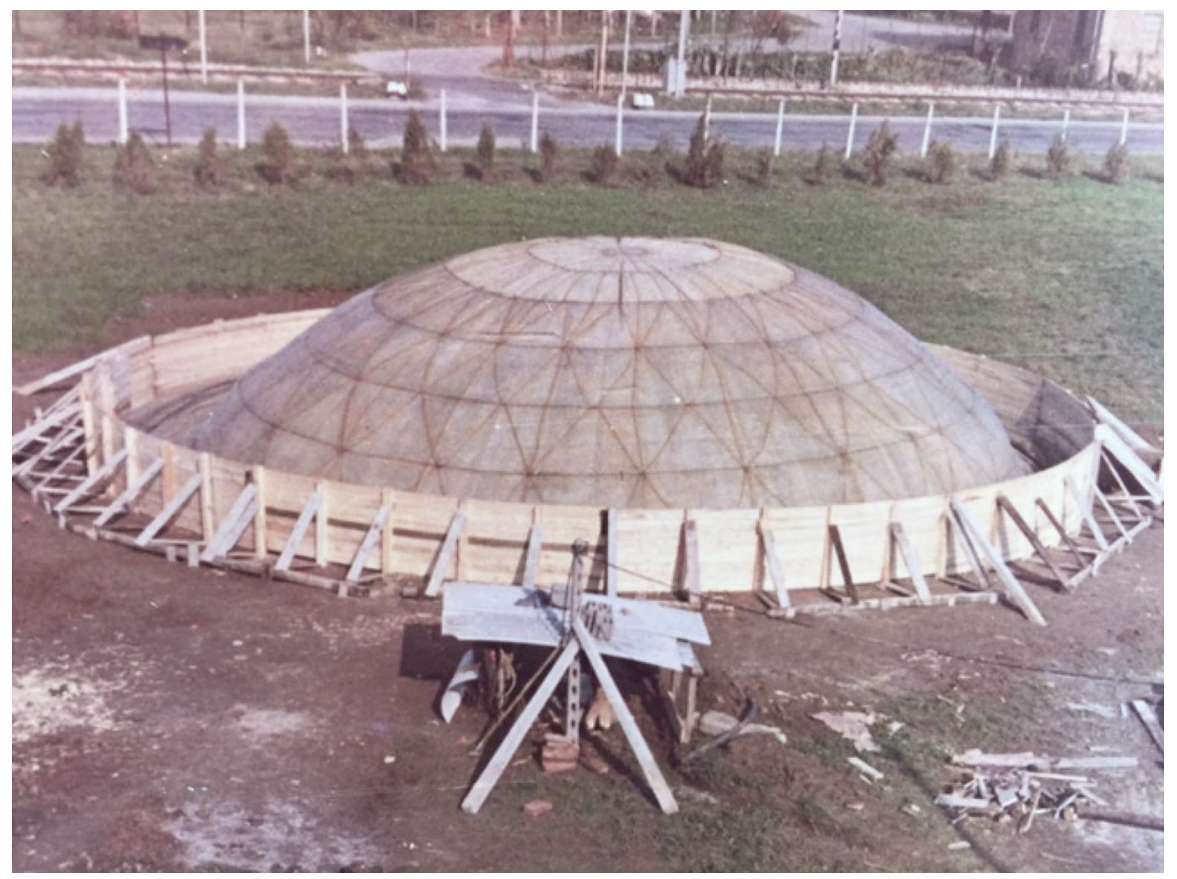

Fig. 4 Early Binishell prototype in Crespellano: notice the rather different design and technology of the reinforcement rods (Photo courtesy of Dante Bini) 


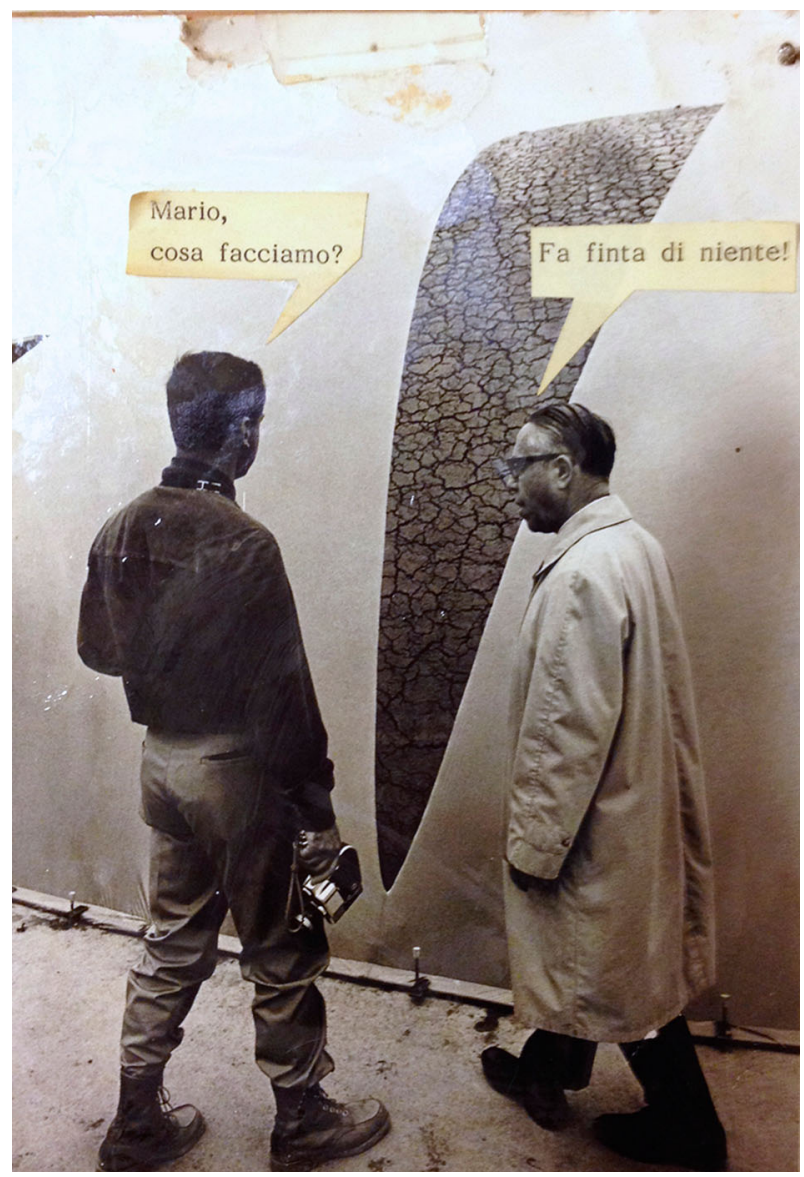

Fig. 5 The development of the Binishell system is also the result of a trial-and-error procedure, which Dante Bini has always approached with irony, for instance making vignettes of this kind. This photograph shows him having a hypothetical conversation with Mario Salvadori on how to "hide" a rather large tear in the outer membrane, which appeared during the erection of a demonstrative Binishell at Columbia University, in front of the press (Courtesy of Dante Bini)

Bini identified eighteen phases during the preparation of a Binishell, requiring from eleven to fourteen days depending on the diameter of the shell. Each of these operations were refined several times over the years; all of these were described, illustrated in great detail and collected by Bini himself in a confidential, unpublished document entitled "Construction Manuals and Schematic Designs" (1995). The last edition of this manual is dated 1995, and serves as an "instruction book" when the Binishell construction technique is licensed for use by foreign companies, as in the case of Jennings Industries in Australia.

It is interesting to note that this document not only contains the secrets of the Binishell system, but also those of two of its closest evolutions: the Minishell system and the Binix system (called Binisix in the manual). Each of these two techniques attempts to solve two problems or aspects-the circular plan and the 
relationship of weight to span-whose solutions are intended to be improvements over the original Binishell system. Both new systems were developed during Bini's stay in Australia from 1976 to 1979. In Sydney, various of Binis's students highlighted the difficulties of distribution of the circular plan, made evident, for instance, in the thesis by Ross Styles (1975). This explains the study of the Minishell system. The motivation behind the experimental, lighter weight shell Binix lay in the desire to cover spans much larger than $40 \mathrm{~m}$. Bini's "Construction Manuals" (Bini 1995) show the Australian designs for the construction of basketball arenas (dated August 1977) measuring $64 \mathrm{~m}$ in diameter, and even a roof for the Port Authority of Freemantle (dated February 1978) with a free span of $100 \mathrm{~m}$. The Minishell system can still be appreciated today, as it is possible to rent a vacation home at Trinity Beach, in Queensland, as well as in various seaside spots in Italy. Binix, instead, remained only a prototype of which few photographs remain (Fig. 6).

Bini, however, did not stop experimenting with new systems for pneumatic lifting to find ways to both cover great spans and substitute reinforced concrete with lighter materials. With the Binistar system, used for example for the press centre of the 1990 FIFA World Cup, he discretised the continuous shell in a steel gridshell that then uses the membrane as its final covering.

We can briefly reflect on the architectonic consequences of these ideas. His most recent projects, like those of his son Nicolò as well, aim at distancing themselves from the original image of "mushroom-shaped" or "space ship" Binishells (the descriptions vary depending on who is being interviewed), which clearly derived from the inflation of the membrane. The results of these efforts do not always succeed in achieving their ends, and in some cases result in images that are even more utopian and futuristic than those of the past.

\section{Developing Domes as Houses}

The use of pneumatic formwork aimed at automatizing the inefficient operations of casting shells in reinforced concrete in place for use as housing, was the object of various kinds of patents (Fig. 7). The first was filed by Walter Neff in 1941, for a single-family dwelling characterised by a cusped dome, with a conspicuous fireplace and wooden inserts to define doors and windows. ${ }^{3}$ In this design Neff also concentrated on the chromatic effects of the dome. Semi-spherical forms were then patented by Neff in 1941 and 1942, ${ }^{4}$ and finally, in 1952, he arrived at a building with a circular plan composed of a cylindrical base and a surbased dome for a roof. ${ }^{5}$

The single- and two-family houses in Falls Church in Virginia, built in 1941, were immediately published in journals for architects and in the popular press alike

\footnotetext{
3 Wallace Neff, "Building construction", US patent 2270229 filed 3 April 1941.

${ }^{4}$ Wallace Neff, "Building construction", US patent 2335300 filed 25 November 1941; Wallace Neff, "Method and apparatus for constructing shell-form structures", US patent 2388701 filed 15 July 1942.

${ }^{5}$ Wallace Neff, "Improved method of erecting shell-form concrete structures", US patent 2892239 filed 19 June 1952.
} 

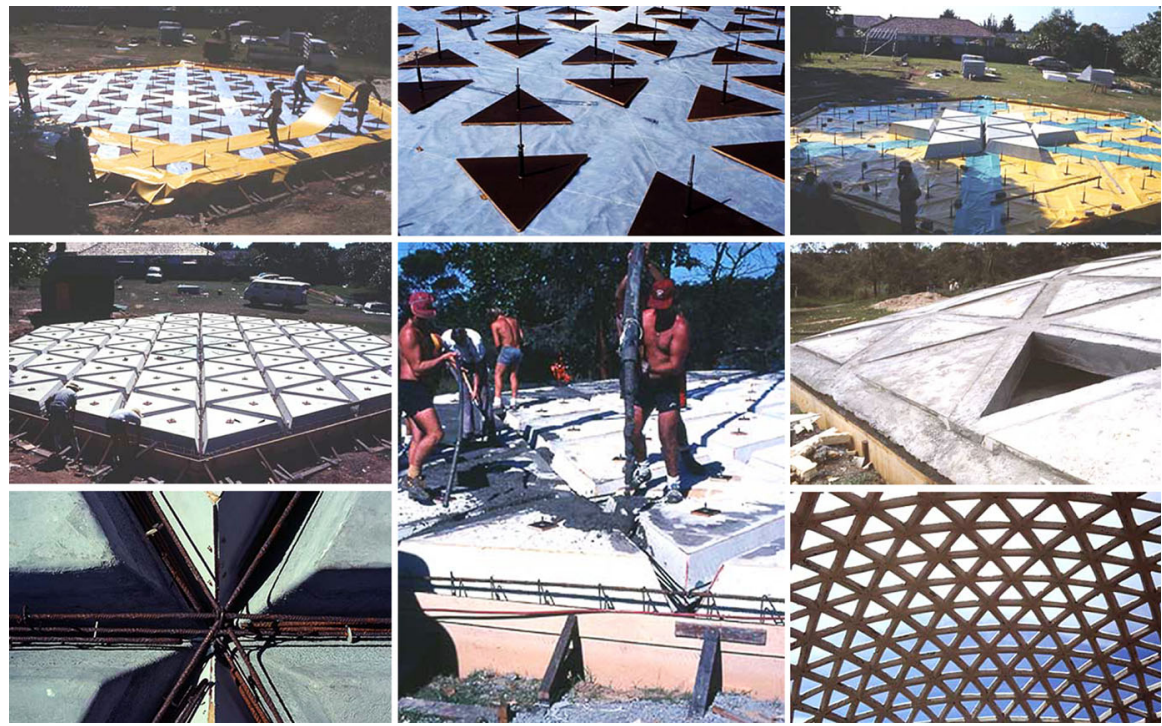

Fig. 6 Construction sequence of a Binix prototype in Australia (Courtesy of Dante Bini)

("Balloon Houses" 1941; "Ballyhooed Balloon" 1941). Such publicity contributed to the immediate success of Neff's inventions, a success which later grew thanks to hundreds of buildings throughout the world erected by his construction company, called the Airform International Construction Company ("Airform House" 1947; Muntz 1989). After the success enjoyed by Neff's "little domes" in the press of the 1950s, there followed later models for residences, again obtained through the use of inflatable, reusable formwork, designed with the collaboration of Noyes ("Semitropical Igloo" 1954; "Air-formed concrete domes" 1954). Some of these structures were quite large in size, and were described and praised by Salvadori (1980: 259-277).

The construction technique patented by Dante Bini is certainly the best suited to the serial production of domes, even with respect that that, certainly better known, filed in 1950 by Nervi. ${ }^{6}$ Nervi's technique was used to realise roofs the world over following the success of the Palazzetto dello Sport in Rome. ${ }^{7}$ His construction system presumes the serial production of basic structural components prefabricated manually (with a series of moulds and formwork on the ground) and then assembled by means of connecting ribs cast in place. It is thus clear that the construction costs are amortised only when production levels are high so that there is a cost benefit in reusing the matrices for large-span roofs. The economy of scale-also realised in the production of flat slabs constructed on models tested for the first time by Nervi's

\footnotetext{
6 Pier Luigi Nervi, "Procedimento di costruzione per la realizzazione di superfici resistenti piane o curve costituite da reticolati di nervature in cemento armato, completate o meno da solette di collegamento tra le nervature", IT patent 465636 filed 19 May 1950.

7 On the evolution of the constructive systems put together by Nervi, see (Gargiani and Bologna 2016). For the characteristics of the dome of the Palazzetto dello Sport in Rome, see (Howard 1966).
} 
Jan. 20, 1942.

W. NEFF

$2,270,229$

BUILDING CONSTRUCTION

Filed April 3, 1941
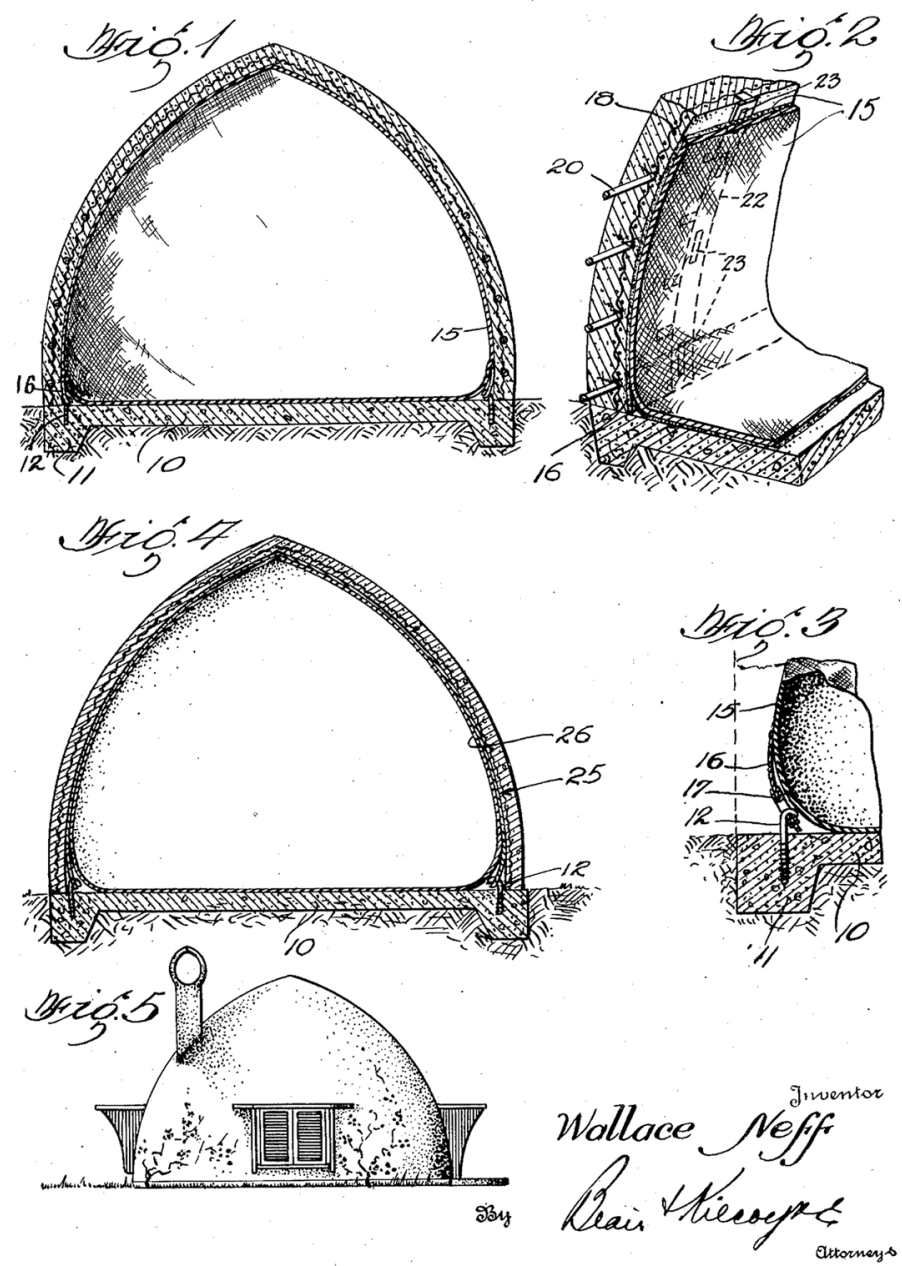

Fig. 7 Cusped dome by Wallace Neff (US patent 2270229)

construction company, Nervi \& Bartoli, in 1949-50 with the building of the warehouse for bales of tobacco at the tobacco manufacturing plant in Bologna, and made famous by the slab of the Gatti wool mill in Rome-lies in the serial reuse of expensive moveable formwork composed of elements in reinforced concrete (capable of guaranteeing the casting of smooth surfaces without imperfections) built according to the same method used for the single-use formwork used by Nervi to build his famous domes (Bologna 2015).

The Bini method was thus born in Italy at the height of the media coverage of the construction system built by Nervi (Bologna 2013). However, the difference 
between the two systems is substantial, and led the two designers/builders to achieve results that we today might, critically speaking, consider diametrically opposed, both formally and commercially. For Nervi, construction in reinforced concrete was always understood as the result of an assembly of parts, and his structures are almost always the offspring of a culture of construction that derived from a masonry tradition. From the earliest systems of construction patented in the 1920 s, to those for the construction of underground reservoirs and the roofs of this famous airplane hangars of the 1930s, to the design developed for the construction of the arch for E42 (the exposition planned to commemorate the twentieth anniversary of Fascism) in the early 1940s, to the patents developed between the end of the 1940s and the beginning of the 1950s for the construction of vaults and domes and used the world over up to the 1980s, Nervi was never able to let go of the concept of a construction that was carried out 'by parts'. There is in fact only a single example in all his work of a shell in reinforced concrete cast in place: the dome of the church of San Marcellino in Genoa, constructed by his own company in 1936 with the use of traditional wooden formwork (Nervi 1965: 102).

Bini took possession of the inspirational concepts that led Nervi to the invention of reinforced concrete over the course of the war, that is, he too understood reinforced concrete as a liquid material that could be molded at will by means of a metal formwork capable of assuming the desired shape. However, for the construction of his domes, Bini was, unlike Nervi, able to detach himself from the masonry tradition that is characteristically Italian. Bini thus reasoned in terms of monolithicity and not assembly. Further, his method made it possible to do almost completely away with temporary equipment on the building site, with the only significant economic investment made in the building of the inflatable formwork, which could be used more than once. This meant that labor was reduced to a minimum of workers trained first to control the pressure of the framework and then to maneuver the mechanical vibrators anchored at the top of the shell. The reduction of the number of workers on site contributed to the success of the Bini's technique and its exportation to other countries, ${ }^{8}$ while the strong component of craftsmanship required for the production of basic prefabricated elements of the domes and vaults designed by Nervi (a process that required highly specialized trained workers) led ultimately to its commercial failure in Italy as well as abroad.

At the end of the 1960s, the need to amortise the initial cost of the pneumatic formwork led Bini and his company, Binishells, to design various structures that could be sold "by catalogue". In so doing Bini was attempting a commercial distribution that Nervi was unable to do, precisely become of the way his construction system worked (Bini 1970). The catalogues produced by the Binishells company show not only Bini's commercial ambitions, but also design research derived from an exploration of geometry and space. This allowed other designers to use the Binishell technique to put their own ideas into practice. What followed was a remarkable experiment in design by various designers throughout Italy, who were

\footnotetext{
${ }^{8}$ See NSW State Records, NRS 435230 02, File no. S5000 1462, where Dante Bini describes to the NSW Department of Public Works how many skilled would be required to export his construction technique in Australia. Bini's proposal was to use three expert workers from his Italian company to train a few local workers in Australia.
} 
capable of building on Bini's patent in ways that concerned architectural expression as well as the distribution of spaces, especially during the five years that followed the construction of the first dome in Crespellano (near Bologna). Examples of this are a vacation home in Naples overseen by the technical studio Edilizia Mediterranea, and the bungalows and residential units of various sizes conceived by the architect Umberto Nordio of Trieste. The architect Riccardo Merlo of Bologna designed an entire scholastic complex, with classrooms composed of domes $20 \mathrm{~m}$ in diameter and a domed gymnasium of $30 \mathrm{~m}$; connections between the various spaces were created by means of suspended walkways. Mario De Franchis was commissioned to build a school for preschoolers in Florence, with a dome $20 \mathrm{~m}$ in diameter and an internal distribution of spaces drawn from Nordio's design. Each dome was personalised by the designer with openings cut out of the finished shell in order to create doors and windows, sometimes intended to bring in light, but other times with purely decorative aims based on formal choices.

Residences designed according to Bini's patent allowed architects to experiment with spatial solutions beginning with "free plans", made possible by the enclosing shell. The proposals by Nordio, the Bolognese architecture studio of BonfiglioliEvangelisti-Vacchi, and the Paris architect Jeleff are, however, based on a rather conventional idea of houses that recalls Nervi's designs for a circular prefabricated house, conceived in 1946 to address post-war housing needs (Nervi 1957: 24-25) and far from the visionary experiments put forth by Friederick J. Kiesler and John M. Johansen. However, a certain degree of experimentation in plan is found in the solutions of the architect Vittorio Casini for a Binishell in La Consuma, near Florence: here the free plan is emphasised by means of a double-height space obtained by means of the insertion of a mezzanine. In another Binishell designed as a restaurant by Nordio, the free plan and the large span are emphasized by the combination and partial superpositioning of five domes, each $15 \mathrm{~m}$ in diameter, thus anticipating by some years the design for the Space City Shopping Centre in Queensland (which was completed in December 1978), and the more recent works of Dante Bini's son Nicolò.

The inherent seriality of the Binishell system constantly led designers to seek plan solutions based on modular criteria. The use of domes of equal diameter, and thus buildable with a single formwork, generated designs that were particularly suggestive, if not always resolved architectonically. Examples are the service station and motel in Rome designed by the architect Anna d'Alessandris Pazzi with the engineer Angelo Berardi, the sporting arena built in Arezzo designed by Bini himself (Bini 1970), and the series of domes $25 \mathrm{~m}$ in diameter built in São Paulo, Brazil, for a proposed nuclear centre.

The use of a single pneumatic formwork is also proposed by Binishells for the serial production of basic structural elements to be used in thin-shell roofs of reinforced concrete for spaces with a square plan (Bini 1970). That we know of, no building has been constructed with this system, but it is easy to intuit how this would make it possible to produce great covered spaces that are prefabricated yet still adaptable (Figs. 8, 9, 10, 11).

In sum, leafing through the commercial catalogues produced by Binishells at the end of the 1960s we find an entire collection of domes destined for uses that range 

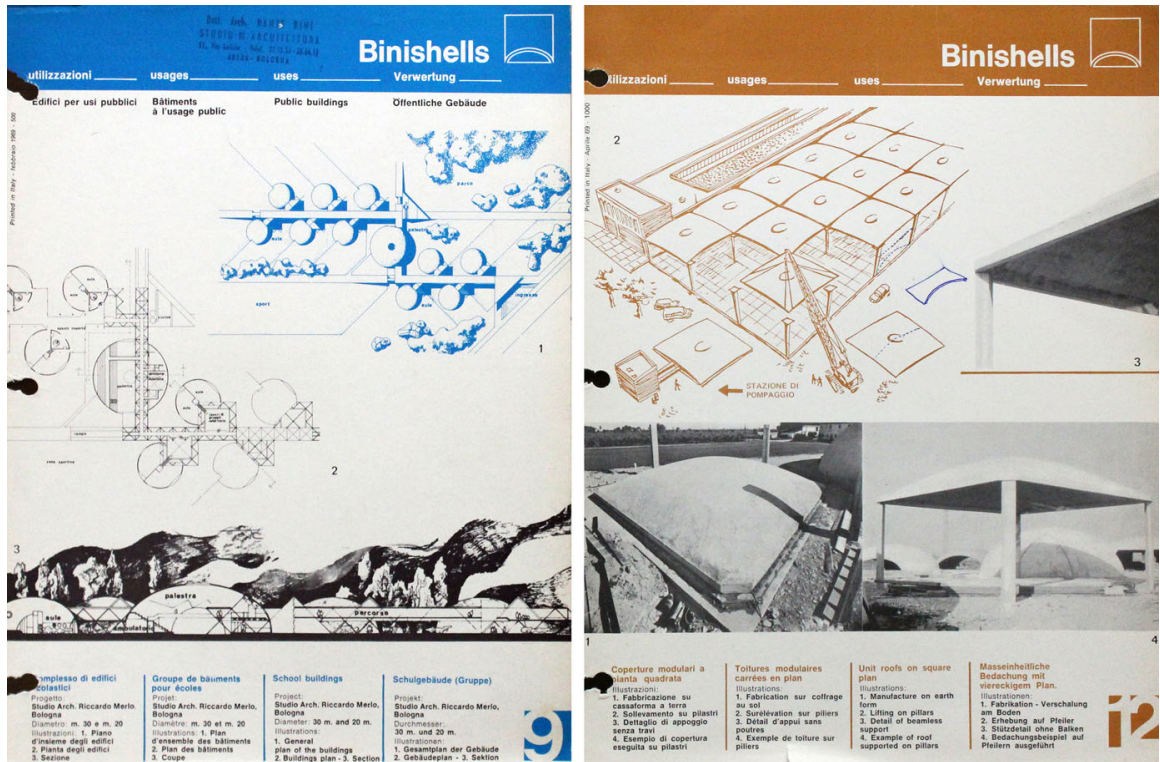

Fig. 8-9 Sample projects from the Binishell Catalogue 1967. On the left, School buildings designed by Riccardo Merlo; on the right, an experimental pneumatic construction technique to build modular roof units on site
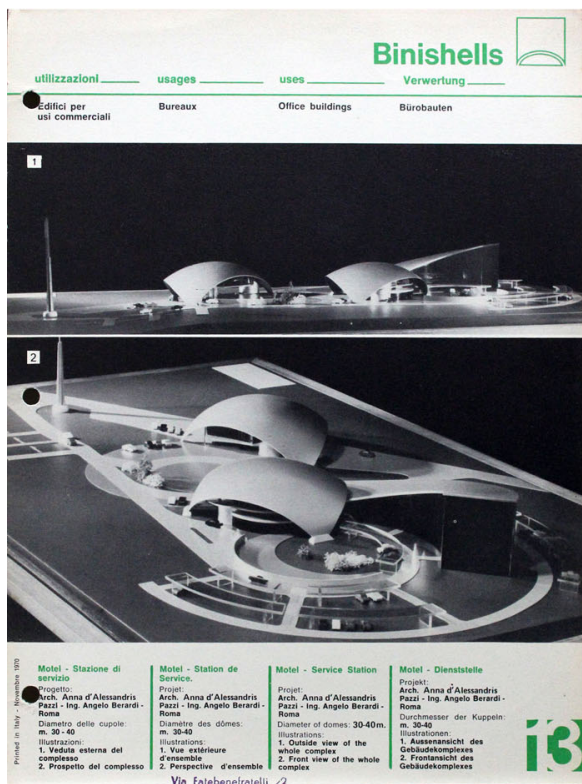

\section{Holst Specialised Structures}

\section{- PARASHELl}

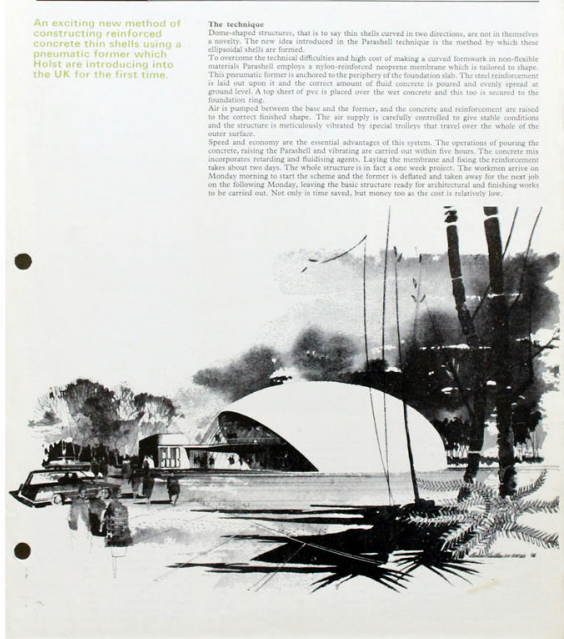

Fig. 10-11 Sample projects from different Binishell catalogues. On the left, Motel for a Service Station designed by Anna d'Alessandris and Angelo Berardi (notice the obvious similarities with the service station on the Bern-Zurich highway by Heinz Isler); on the right, the Binishell system was sometimes licensed under a different names abroad, for instance as "Parashell" 
from office buildings (such as those built in Crespellano and Parma for the companies Unipack and Impresa Conciari) to sheds for industrial use (such as those built in Imperia). Copies of these catalogues are still conserved today in Dante Bini's private archive in California, and they are excellent witnesses the widespread activities of the Binishell company in Italy and abroad as early as 1967.

\section{Why Binishells Fall Down}

In 1992, twelve years after Why Buildings Stand Up, Salvadori and Matthys Levy, who Salvadori himself called "a master of structural design" (Levy and Salvadori 1992: 9), teamed up to write a new book on architectural engineering entitled Why Buildings Fall Down: How Structures Fail. The aim was "explaining structural failures in lay language" (Levy and Salvadori 1992: 9). The authors developed the text beginning with the premise that "a building is conceived when designed, born when built, alive while standing, dead from old age or an unexpected accident" (Levy and Salvadori 1992: 13) and that "as medical doctors consider health to be the norm and disease the exception, and gain most of their knowledge from illness, so engineers consider standing buildings the norm and structural failures the exception, although they learn a lot from failures" (Levy and Salvadori 1992: 14). Here Bini is defined as "without a doubt the builder of the largest number of domes in history", and the authors attribute to him more than 1500 buildings with spans from 7.5 to $90 \mathrm{~m}$ in twenty-three different countries (Levy and Salvadori 1992: 38).

In Italy in 1975 the Binishells company offered, for a price of six million lire (about $\$ 9200$ US at the time) a single-family dome house $12 \mathrm{~m}$ in diameter, consisting of a kitchen, living room, three bedrooms and two bathrooms. It could be built in only six working days, and was advertised in the popular press as "a small home of the latest conception" (Olivieri 1975). That construction system did not take off in the residential market, in spite of the efforts by Bini and his company to publicise it (Fig. 12). However, Binishells did carve out a niche, albeit a small one, for small-diameter domes for use in vacation villages, first in Italy and then in Australia.

In both Italy and the United States, Binishell systems for the construction of domes enjoyed a lukewarm success, at least for buildings ordered "by catalogue". Salvadori and Levy account for the cool reception in this way:

Eighty percent of one-family housing in the United States is built by the owners, who are not professional builders. Most of these houses come to the site completely finished on a trailer or a prefabricated in a factory and assembled on-site in a few days. In this environment, buildings with a circular plan present difficulties for the insertion of standard windows and doors as well as for placement of furniture conceived for rooms with a rectangular plan (Levy and Salvadori 1992: 40-41).

From 1974 to 1980, Bini lived and worked in Australia, where he was employed by the Department of Public Works in New South Wales. He built some twenty domes for libraries and multi-purpose centres for public schools, and at least another 


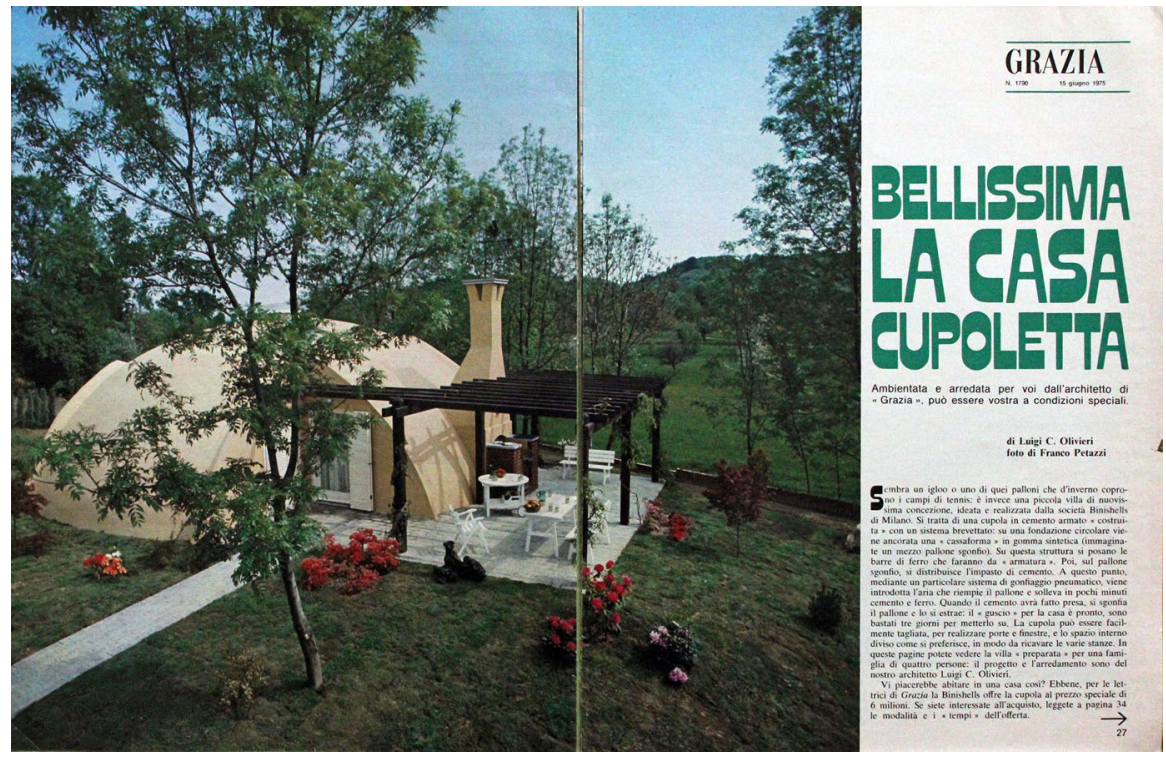

Fig. 12 Article by Luigi Olivieri on Binishell houses, published on the Italian weekly women's magazine "Grazia" (Grace) no. 1790 (June 1975): 26-33

ten private Binishells, licensing his patent to a local company, Jennings Industries. Together, Bini and Jennings beat the record for the largest Binishell complex in the world, with the construction, outside of Brisbane, in Australian, of the Space City Shopping Centre, unfortunately demolished (Jennings Industries 1978). However there was also a couple of unexpected collapses, which occurred in the space of ten years, the first a school in Fairvale, the second in Pittwater. The first structural failure led a group of parents to manifest preoccupation about the actual safety of the Binishell system and therefore, between 1975 and 1986, precautionary support towers were installed in the other Australian 36 m. diameter domes (Figs. 13, 14). After the second collapse in Pittwater, permanent steel structures were added to prevent future failures, but thoughts about possible Binishell replacements also began to arise (Pugnale and Bologna 2015).

In the case of buildings destined for use as residences Bini was certainly not able to achieve the results hoped for at the beginning of the 1970s and promoted in the Binishell catalogues, either in terms of the quantity of domes produced or with regard to the degree of architectural experimentation prefigured with the first prototypes. He was therefore not able to follow iconic episodes with meaningful sequels; the earliest examples, such as the famous villa built for film director Michelangelo Antonioni and actress Monica Vitti in Costa Paradiso, Sardinia, remained memorable but isolated gestures. It is probable that the analysis of this moderate success, at least as far as the building of homes is concerned, lies in the interpretation of Salvadori and Levy: "curved spaces are alien to our culture for historic reasons that have produced inherited psychological prejudices" (Levy and Salvadori 1992: 41). 


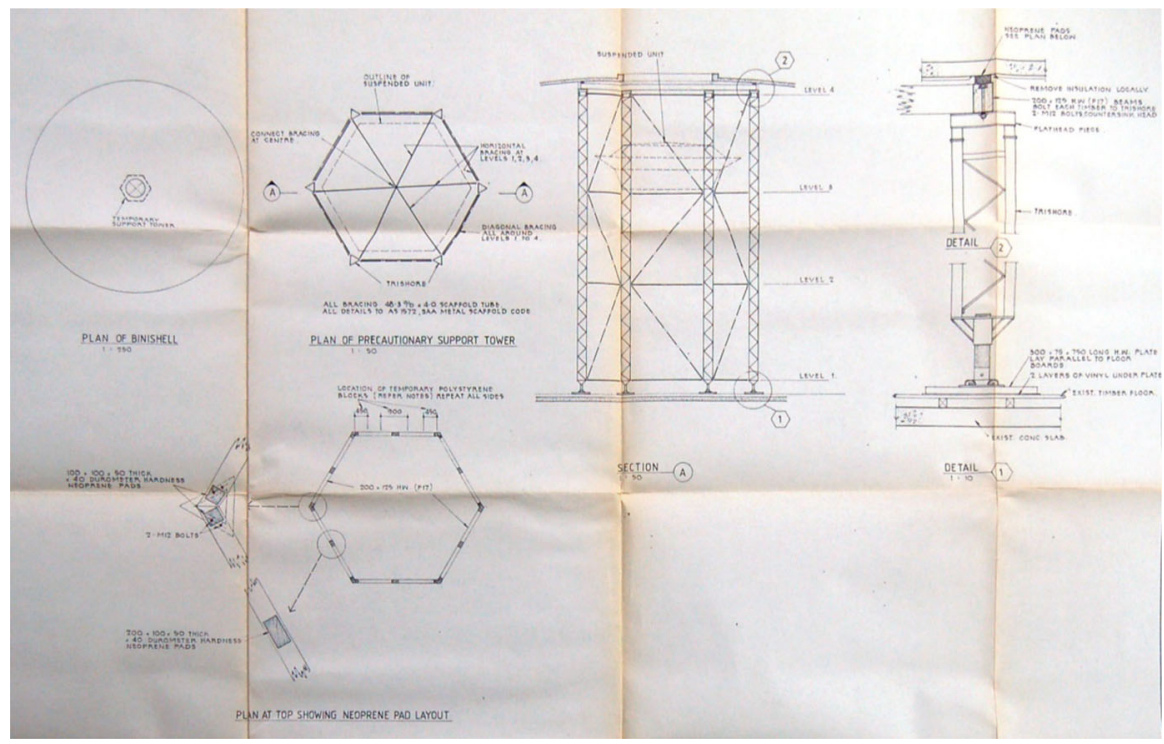

Fig. 1336 Metre Binishell Precautionary Support Tower designed by Taylor Thomson Whitting Consulting Structural \& Civil Engineers (Monash University Archives)

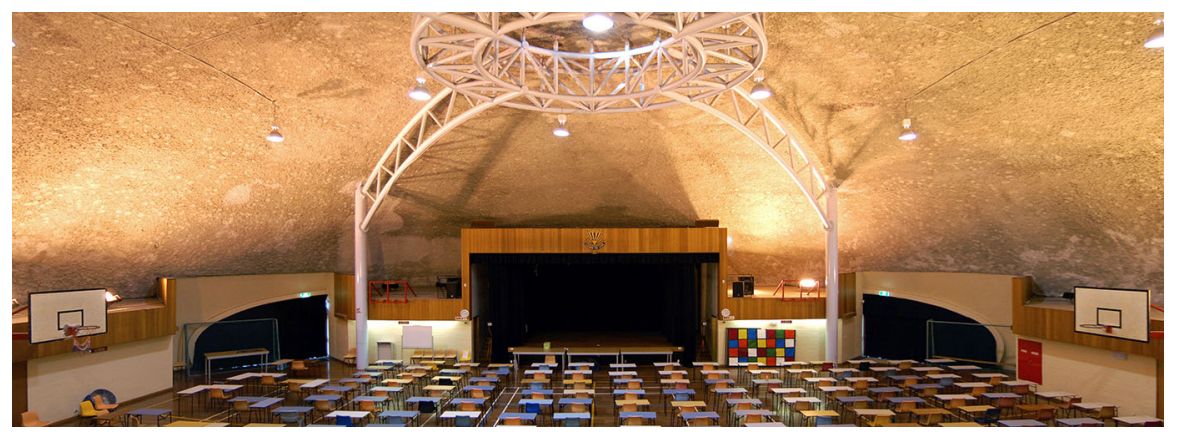

Fig. 14 Permanent steel structure installed at Fairvale High School. Photo by Alberto Pugnale

The search for prefabrication/automatization of construction sites at any cost is another of the factors that have stimulated Bini to develop new systems while at the same time limiting him to the generation of new patents that all draw on the same idea: the erection of form-resistant structures by means of the exclusive use of pneumatic formwork.

Translated from the Italian by Kim Williams.

Acknowledgements This paper is the result of an ongoing research project on Binishells, which was funded in 2013 by the Faculty of Architecture, Building and Planning of the University of Melbourne, and of which A. Pugnale is Chief Investigator.The paper structure and narrative are the result of the combined work of the two authors. Section 1 and 3 were drafted by A. Bologna and edited by A. Pugnale; Section 2 was written by A. Pugnale and reviewed by A. Bologna. Section 4 contains conclusive reflections by both authors. The Australian and American fieldworks were carried out by A. Pugnale, between May 2014 and 
June 2016, and include visits to several Australian Binishells, digitalisation of the archival sources of the NSW State Records, as well as of Dante Bini's private archive, which is currently stored in St. Helena, Napa Valley, CA, USA. The Italian fieldwork was carried out by A. Bologna, who also took care of the filed patents on the topic. The authors consider their individual contribution to the paper with an equal percentage of $50 \%$. The authors would also like to express their gratitude to Dante Bini, for his generous hospitality, for providing us access to his personal archive in St. Helena, CA, USA, and permitting the publication of personal photographs and documents.

\section{References}

“Airform House is improved for U.S. market, also going overseas." The Architectural Forum, July 1947: 15.

"Air-formed concrete domes. House Hobe Sound, Florida." Progressive Architecture, June 1954: 116-119.

"Balloon Houses Designed for Defense Workers Bloom Under Virginia Trees.” Life, December, 1, 1941: 34-35.

"Ballyhooed Balloon.” The Architectural Forum, December 1941: 421.

Bettazzi, M. Beatrice and Paolo Lipparini (eds.). 2010. Attilio Muggia. Una storia per gli ingegneri. Bologna: Compositori.

Bini, Dante. 1968. Metodo per la erezione di edifici e strutture a membrana monolitica perfezionato nel complesso della armatura estensibile nonché nella compattazione del materiale. Italian patent no. IT 853736, filed 21 November 1968.

Bini, Dante. 1970. catalogo commerciale Binishells (commercial catalogue printed in Italy in June 1970). From the private archive of Dante Bini, St. Helena, Napa Valley, CA, USA.

Bini, Dante. 1995. Folding Pneumoform and placing P.V.C. Sheets. In "Self-Shaping Reinforced Concrete Structures: Binishell, Minishell and Binix. Construction Manuals and Schematic Designs", licensed to Jenning Industries Limited in Australia by Bini Consultants Australia (Unpublished).

Bologna, Alberto. 2013. Pier Luigi Nervi negli Stati Uniti. 1952-1979: 'Master Builder of the Modern Age'. Florence: Firenze University Press.

Bologna, Alberto. 2015. "Structural Art" in Nervi \& Bartoli's Industrial Architecture (1949-1971). In: Jeannette Kuo (ed.), Space of Production. Projects and essays on rationality, atmosphere, and expression in the industrial building, 90-97. Zurich: Park Books.

Gargiani, Roberto and Alberto Bologna. 2016. The Rhetoric of Pier Luigi Nervi. Concrete and Ferrocement Forms. Lausanne: EPFL Press and Oxford: Routledge.

Guccione, Margherita (ed.). 2003., Il ponte e la città. Sergio Musmeci a Potenza. Rome: Gangemi.

Howard, H. Seymour, Jr. 1966. Structure: An Architect's Approach. New York: McGraw-Hill.

Isler, Heinz. 1994. Concrete Shells Derived from Experimental Shapes. Structural Engineering International 3: 142-147.

Jennings Industries (contributor). 1978. Binishells. The Chartered Builder 25: 29-43.

Jones, Victor J. 2015. Basento. Un ponte, Leonforte: Euno Edizioni.

Levy, Matthys and Mario Salvadori. 1992. Why Buildings Fall Down. How Structures Fail. New York: W.W. Norton.

Manfredi, Nicoletti. 1999. Sergio Musmeci: Organicità di forme e forze nello spazio. Torino: Testo \& Immagine.

Marsh, James H. 1964. Construction of thin shell structures by the "lift-shape" process, in S. J. Medwadowski (ed.), Proceedings. World Conference on Shell Structures, 447-452. Washington D.C.: National Academy of Sciences, National Research Council.

McLean, Will. 2013. Domes of Discovery. Architectural Review 233(1392) (February 2013): 86-93.

McLean, Will. 2016. Building with Air: The Pneumatically Powered Construction Systems of Dante Bini. In: James Campbell, et al. (eds.), Further Studies in the History of Construction. The Proceedings of the Third Annual Conference of the Construction History Society (Cambridge, 8-10 April 2016), 441-450. The Construction History Society.

Medwadowski, S. J. (ed.). 1964. Proceedings. World Conference on Shell Structures (1-4 October 1962, San Francisco), National Academy of Science, Washington, D.C.

Mohr, Normand W. 1927. The city of Saint Francis idealized. The Architect and Engineer 88(2) (Feb. 1927): 83-84. 
Moreyra Garlock, Maria E. and David P. Billington. 2008. Félix Candela: Engineer, Builder, Structural Artist. Princeton University Art Museum Monographs. New Haven: Yale University Press.

Muntz, J. F. 1989. Bubbles for defense, in Wallace Neff 1895-1982. The Romance of Regional Architecture. San Marino, CA: The Huntington Library.

Nervi, Pier Luigi. 1957. The Works of Pier Luigi Nervi. London: The Architectural Press.

Nervi, Pier Luigi. 1965. Aesthetics and Technology in Building. The Charles Eliot Norton Lectures, 1961-1962. Cambridge, MA: Harvard University Press.

Ochsendorf, John. 2010. Guastavino Vaulting: The Art of Structural Tile. New York: Princeton Architectural Press.

Olivieri, Luigi C. 1975. Bellissima la casa cupoletta. Grazia no. 1790 (June 1975): 26-33.

Pugnale, Alberto and Alberto Bologna. 2015. Dante Bini's 'New Architectural Formulae': Construction, Collapse and Demolition of Binishells in Australia 1974-2015. In: Paul Hogben and Judith O'Callaghan, Proceedings of the Society of Architectural Historians, Australia and New Zealand: 32, Architecture, Institutions and Change, 488-499. Sydney: SAHNZ.

Ramm, Ekkehard. 2011. Heinz Isler Shells-The Priority of Form. Journal of the International Association for Shell and Spatial Structures 52(3): 143-154.

Salvadori, Mario and Robert Heller. 1963. Structure in Architecture, Prentice-Hall Inc., Englewood Cliffs, New Jersey, 1963.

Salvadori, Mario. 1980. Why buildings stand up. The strength of architecture. New York, London W.W. Norton.

Salvadori, Mario. 1997. Paper bridges. Strength Through Form. New York: Salvadori Center.

Scipio L. A. 1967. Structural Design Concepts. Some NASA contributions, Technology Utilization Division, National Aeronautics and Space Administration, Washington DC.

"Semitropical Igloo. 'Bubble House' is the new version of a practical cement dwelling for \$6,500". Life, February 22, 1954: 75-76.

Styles, Ross. 1975. Binishells. Bachelor's thesis, University of New South Wales.

Thrall, Ashley P. and Maria E. Moreyra Garlock. 2010. Analysis of the Design Concept for the Iglesia de la Virgen de la Medalla Milagrosa. Journal of the International Association for Shell and Spatial Structures 51(1): 27-34.

Todisco, Leonardo, Giuseppe Sanitate and Giuseppe Lacorte. 2017. Proportions of the Traditional Trulli of Alberobello. Nexus Network Journal. doi:10.1007/s00004-016-0326-4.

\begin{abstract}
Alberto Pugnale is an architect, Ph.D. and Senior Lecturer in Architectural Design at the 'Faculty of Architecture, Building and Planning' of the University of Melbourne. In 2007 he won the IASS HANGAI Prize, an international contest of research papers that are related to the field of shell and spatial structures for young researchers. In 2008 he won a research scholarship granted by the ISI Foundation (Turin, Italy), related to the study of complex architectural and structural bodies. From 2010 to 2012 he was Assistant Professor at Aalborg University, Denmark. He has been teaching as invited lecturer in Italy, France and China. At present, he is member of the 'International Association for Shell and Spatial Structures' (IASS), of the 'Architecture Science Association' (ASA) and of the 'Society of Architectural Historians Australia and New Zealand' (SAHANZ). He is also reviewer of several international journals.
\end{abstract}

Alberto Bologna is an architect and obtained his Ph.D. in "History of architecture and town planning" in 2011 at Politecnico di Torino with a thesis on the US activities of Pier Luigi Nervi. From 2011 to 2015 he has been a researcher at the École polytechnique fédérale de Lausanne (EPFL) where he developed research projects on the relationship between architectural form and building technique. At present, he teaches Architectural Design as Adjunct Professor at Politecnico di Torino, Politecnico di Milano and the University of Ferrara. Since 2015 he is the director and co-organiser of the international architecture summer school "Sewing a small town". He is the author of several scientific articles and three books: "Pier Luigi Nervi negli Stati Uniti. 1952-1979. Master builder of The modern age" (2013), "Pier Luigi Nervi ou 1'art de la structure" (2013) and "The rhetoric of Pier Luigi Nervi. Concrete and ferrocement forms" (2016, with Roberto Gargiani). 